\title{
Asymmetric reduction of racemic sulfoxides by dimethyl sulfoxide reductases from Rhodobacter capsulatus, Escherichia coli and Proteus species
}

\author{
Steven P. Hanlon, ${ }^{1} \dagger$ Daniel L. Graham, ${ }^{2} \ddagger$ Philip J. Hogan, ${ }^{3}$ \\ Robert A. Holt, ${ }^{2}$ Christopher D. Reeve, ${ }^{2}$ Anthony L. Shaw ${ }^{4}$ \\ and Alastair G. McEwan ${ }^{4}$
}

\begin{abstract}
Author for correspondence: Alastair G. McEwan. Tel: +6173365 4878. Fax: +61733654620 .
\end{abstract} e-mail: mcewan@biosci.uq.edu.au

1 School of Biological Sciences, University of East Anglia, Norwich NR4 7TJ, UK

2 Zeneca LifeScience Molecules, Belasis Avenue, Billingham, Cleveland TS23 IYN, UK.

3 Zeneca Pharmaceuticals, Macclesfield, Cheshire, SK10 2NA, UK

4 Department of Microbiology, The University of Queensland, Brisbane 4072, Australia

\begin{abstract}
The enantioselective reduction of racemic sulfoxides by dimethyl sulfoxide reductases from Rhodobacter capsulatus, Escherichia coli, Proteus mirabilis and Proteus vulgaris was investigated. Purified dimethyl sulfoxide reductase from Rhodobacter capsulatus catalysed the selective removal of (S)-methyl p-tolyl sulfoxide from a racemic mixture of methyl p-tolyl sulfoxide and resulted in an $88 \%$ recovery of enantiomerically pure $(R)$-methyl $p$-tolyl sulfoxide.

Rhodobacter capsulatus was shown to be able to grow photoheterotrophically in the presence of certain chiral sulfoxides under conditions where a sulfoxide is needed as an electron sink. Whole cells of Rhodobacter capsulatus were shown to catalyse the enantioselective reduction of methyl p-tolyl sulfoxide, ethyl 2-pyridyl sulfoxide, methylthiomethyl methyl sulfoxide and methoxymethyl phenyl sulfoxide. Similarly, whole cells of Escherichia coli, Proteus mirabilis and Proteus vulgaris reduced these sulfoxides but with opposite enantioselectivity.
\end{abstract}

Keywords: dimethyl sulfoxide reductases, racemic sulfoxides, enantioselectivity

\section{INTRODUCTION}

The importance of chirality to the specificity of drug action is well documented. For example, the activity of the $(S)$-enantiomer of the $\beta$-receptor antagonist propanolol is approximately 100 -fold that of the $(R)$ enantiomer (Bevinakatti \& Banerji, 1991; Crosby, 1992). A valuable chemical group which can be used in chiral drug synthesis is the sulfoxide. When substituted with two different groups the sulfoxide is chiral by virtue of the presence of a lone pair of electrons on the sulfur atom. Optically active sulfoxides have been used as functional groups in drugs (see Pitchen et al., 1994, for example) and also as reagents for the control of

†Present address: Molecular Pharmocology Unit, Ninewells Hospital and Medical School, Dundee DD1 95Y, UK.

¥Present address: Department of Biochemistry, University College, Gower Street, London WC1E 6BT, UK.

Abbreviations: DMSO, diemthyl sulfoxide; EPSO, ethyl 2-pyridyl sulfoxide; FMN, flavin mononucleotide; MMPSO, methoxymethyl phenyl sulfoxide; MPTSO, methyl $p$-tolyl sulfoxide; MTMSO, methylthiomethyl methyl sulfoxide; TMAO, trimethylamine- $\mathrm{N}$-oxide. diastereoselective reactions at adjacent substituents (Carreno, 1995; Butlin et al., 1996). The development of methods for the production of optically pure compounds is a rapidly expanding industry in which enzymes play a central role (Roberts et al., 1995). Although a number of chemical methods for the production of optically active sulfoxides have been investigated (Solladie, 1981; Carreno, 1995) biological approaches have also been applied. For example, racemic sulfoxides containing an ester group have been resolved using ester hydrolase (Burgess et al., 1992) and prochiral sulfides have been asymmetrically oxidized by both whole cells (Rossi et al., 1992; Holland, 1988; Holland et al., 1995) and isolated enzymes (Colonna et al., 1990).

An alternative approach to the preparation of optically active sulfoxides is the enantioselective reduction of racemic sulfoxides by $S$-oxide reductases. Bacterial $S$ oxide reductases are widely distributed among facultative aerobic bacteria, where they function as the terminal enzyme in an anaerobic respiratory chain (McEwan et al., 1991; Weiner et al., 1992). The dimethyl sulfoxide (DMSO) reductase (DmsABC) from Escher- 
ichia coli is a membrane-bound enzyme which catalyses electron transfer from menaquinol to a wide variety of $S$-oxides and $N$-oxides (Weiner et al., 1988; SimalaGrant \& Weiner, 1996). The enzyme is composed of three subunits: a catalytic subunit (DmsA) which contains a pterin molybdenum cofactor, a subunit which contains four $[4 \mathrm{Fe}-4 \mathrm{~S}]$ clusters $(\mathrm{DmsB})$ and a membrane-bound anchor subunit (DmsC) (Weiner et al., 1992). The second type of DMSO reductase is a periplasmic enzyme which terminates a respiratory chain in purple phototrophic bacteria such as Rhodobacter capsulatus (McEwan et al., 1985) and R. sphaeroides (Satoh \& Kurihara, 1987). This enzyme also contains a pterin molybdenum cofactor (McEwan et al., 1991), and high-resolution X-ray crystallographic structures of this DMSO reductase have been reported (Schindelin et al., 1996; Schneider et al., 1996; McAlpine et al., 1997).

Sequence analysis of the $R$. capsulatus DMSO reductase has shown that it is more closely related to the periplasmic trimethylamine- $\mathrm{N}$-oxide (TMAO) reductase (TorA) from E. coli rather than DmsA (Shaw et al., 1996) and for this reason we refer to the Rhodobacter DMSO reductase as DorA. In contrast to the E. coli TorA, which exhibits a high $k_{\text {cat }} / K_{\mathrm{m}}$ ratio with only a few $N$-oxides (Iobbi-Nivol et al., 1996), DorA has a relatively broad substrate specificity towards $S$-oxides and $N$-oxides (Satoh \& Kurihara, 1987). It has been established that DorA is enantioselective when reacting with chiral sulfoxides (Hanlon, 1993; Abo et al., 1994, 1995) but nothing is known about the enantioselectivity of DmsABC. In this paper we describe the reaction of chiral sulfoxides with purified DorA from $R$. capsulatus and the enantioselective reduction of chiral sulfoxides by cells of $R$. capsulatus, E. coli and Proteus species.

\section{METHODS}

Chemicals. The structures of the $S$-oxides used in this study are shown in Fig. 1. Hydrogen peroxide, $m$-chloroperbenzoic acid, sodium periodate, methyl $p$-tolyl sulfoxide (MPTSO) (pure enantiomers), methyl $p$-tolyl sulfide, methoxymethyl phenyl sulfide, methylthiomethyl methyl sulfoxide (MTMSO), bis(methylthio)methane, tert-butyl methyl sulfide, DL-methionine sulfoxide, dimethyl sulfoxide, 2-mercaptopyridine and ethyl bromide were obtained from Aldrich. Sulfides and sulfoxides not commercially available were synthesized as follows.

tert-Butyl methyl sulfoxide. tert-Butyl methyl sulfide $(1.5 \mathrm{~g})$ was added to glacial acetic acid $(50 \mathrm{ml})$ at room temperature and stirred. An equimolar equivalent of hydrogen peroxide (30 wt $\%$ in water) was added over a period of $4 \mathrm{~h}$ whilst maintaining the temperature below $20^{\circ} \mathrm{C}$. After a further $1 \mathrm{~h}$ the reaction was diluted with water $(200 \mathrm{ml})$ and then extracted with dichloromethane $(250 \mathrm{ml})$. The organic layer was recovered and washed successively with equal volumes of water, $0.5 \mathrm{M}$ sodium hydrogen carbonate and water. The organic layer was dried with anhydrous sodium sulfate and the solvent removed under reduced pressure to yield tert-butyl methyl sulfoxide as a clear oil.

Methoxymethyl phenyl sulfoxide (MMPSO). Methoxymethyl phenyl sulfide $(5 \cdot 1 \mathrm{~g})$ was added to dichloromethane $(100 \mathrm{ml})$ and stirred on ice. $m$-Chloroperbenzoic acid $(7 \cdot 7 \mathrm{~g})$ was dissolved

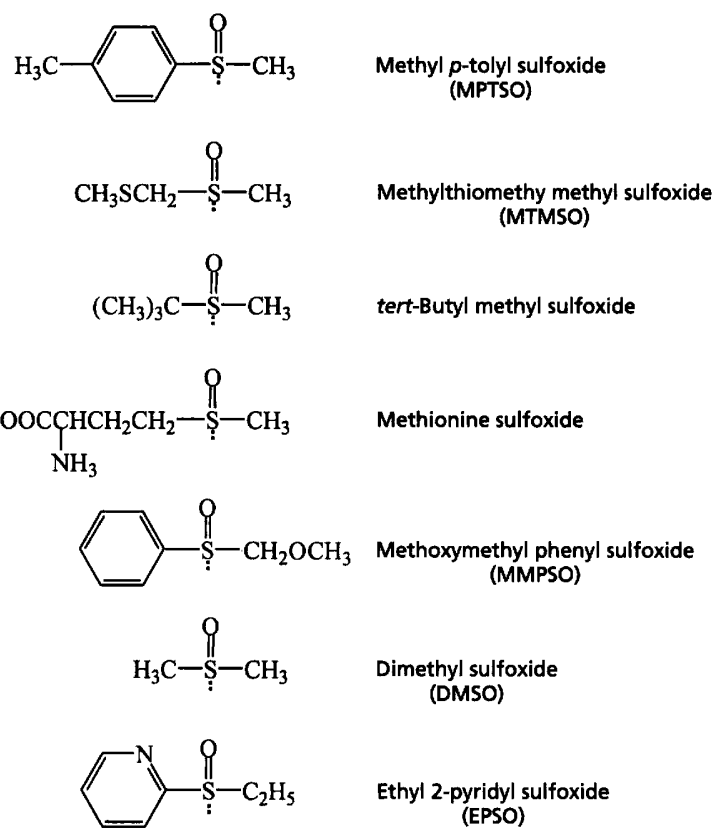

Fig. 1. Structures of S-oxides used in this study.

in dichloromethane $(120 \mathrm{ml})$ and added dropwise to the sulfide solution over a period of $1 \mathrm{~h}$. The reaction was stirred for $3 \mathrm{~h}$ then washed successively with aqueous $10 \%$ sodium sulfite $(2 \times 50 \mathrm{ml})$ and water $(2 \times 50 \mathrm{ml})$. The dichloromethane layer was dried with anhydrous sodium sulfate and evaporated under reduced pressure to yield a yellow oil $(5 \cdot 7 \mathrm{~g})$. Residual sulfide was removed by purification on a $30 \mathrm{~g}$ silica gel column (Kieselgel 60, Merck) eluted with ethylacetate/hexane $(1: 1$, $\mathrm{v} / \mathrm{v}$ ) to yield $1.3 \mathrm{~g}$ of a clear, odourless oil.

Ethyl 2-pyridyl sulfoxide (EPSO). To a solution of 2-mercaptopyridine $(17.85 \mathrm{~g})$ in $\mathrm{N}$-methylpyrrolidone $(250 \mathrm{ml})$ was added $49 \%$ aqueous potassium hydroxide $(9 \mathrm{ml})$. Ethyl bromide $(16.2 \mathrm{ml})$ was added over $7 \mathrm{~min}$ whilst maintaining the temperature below $30^{\circ} \mathrm{C}$ (a white solid precipitated). The stirred reaction was heated to $85^{\circ} \mathrm{C}$ for $3 \mathrm{~h}$ then allowed to cool to $20^{\circ} \mathrm{C}$ over $15 \mathrm{~h}$. Toluene $(320 \mathrm{ml})$ and water $(320 \mathrm{ml})$ were added to the mixture resulting in a temperature rise to $34^{\circ} \mathrm{C}$. The mixture was cooled to $20^{\circ} \mathrm{C}$ and the aqueous phase adjusted to $\mathrm{pH} 11$ by the dropwise addition of $49 \%$ potassium hydroxide $(\sim 6 \mathrm{ml})$. The organic and aqueous layers were separated and the aqueous phase $(566 \mathrm{ml})$ reextracted with toluene $(160 \mathrm{ml})$. The organic phase was washed with $2 \mathrm{M}$ sodium hydroxide $(2 \times 160 \mathrm{ml})$ and water $(2 \times 160 \mathrm{ml})$. The recovered organic phase was evaporated under reduced pressure to yield $23.04 \mathrm{~g}$ of a yellow oil. A sample of the oil $(22.71 \mathrm{~g})$ was transferred to a $50 \mathrm{ml}$ flask and distilled at $80 \mathrm{mmHg}$ pressure using a $5 \mathrm{~cm}$ Vigreux column; the product, ethyl 2-pyridyl sulfide, distilled at a head temperature of $124-125^{\circ} \mathrm{C}$. The sulfide $(18.1 \mathrm{~g})$ was mixed with methanol $(26 \mathrm{ml})$ and added dropwise to an aqueous solution of sodium periodate $(29.6 \mathrm{~g}$ in $278 \mathrm{ml})$ over $20 \mathrm{~min}$ whilst maintaining the temperature at $0-3{ }^{\circ} \mathrm{C}$. The periodate addition funnel was washed with a further $26 \mathrm{ml}$ of methanol, which was added to the reaction over $5 \mathrm{~min}$. The reaction was held at $0{ }^{\circ} \mathrm{C}$ for $44 \mathrm{~h}$, filtered, and the filter cake washed with water $(63 \mathrm{ml})$. The combined filtrate was extracted with dichloromethane $(3 \times 160 \mathrm{ml})$ and the solvent evaporated under reduced pressure to give a colourless oil $(19.5 \mathrm{~g})$. The 
crude sulfoxide was purified by fractional distillation under reduced pressure $\left(4 \mathrm{mmHg}, 131-132{ }^{\circ} \mathrm{C}\right)$.

Micro-organisms and growth. Bacteria used in this study were Escherichia coli ATCC 33694, Rhodobacter capsulatus DSM 938 (also known as 37b4), R. capsulatus H123 (Hudig et al., 1986), Proteus vulgaris NCIMB 67 and Proteus mirabilis NCIMB 8268. For chemoheterotrophic growth microorganisms were typically grown in a basal medium of the following composition $\left(\mathrm{g} \mathrm{l}^{-1}\right)$ : $\mathrm{NaH}_{2} \mathrm{PO}_{4}, 1.56 ; \mathrm{K}_{2} \mathrm{HPO}_{4}, 1 \cdot 9$; $\left(\mathrm{NH}_{4}\right)_{2} \mathrm{SO}_{4}, \quad 1 \cdot 8 ; \quad \mathrm{MgSO}_{4} .7 \mathrm{H}_{2} \mathrm{O}, \quad 0 \cdot 2 ; \quad \mathrm{FeCl}_{3}, \quad 0.005 ;$ $\mathrm{Na}_{2} \mathrm{MoO}_{4} \cdot 2 \mathrm{H}_{2} \mathrm{O}, 0.001$; yeast extract, 2 or Casamino acids, 1. After autoclaving, the following components were added as a filter-sterilized solution (final concentrations $\mathrm{g} \mathrm{l}^{-1}$ ): thiamin. $\mathrm{HCl}, 0.03$; nicotinic acid, 0.007; DMSO, 5.5. Trace elements solution $\left(1 \mathrm{ml} \mathrm{l}^{-1}\right)$ was also added to the medium. The stock trace elements solution contained $\left(\mathrm{g} \mathrm{l}^{-1}\right)$ : $\mathrm{CuSO}_{4} .5 \mathrm{H}_{2} \mathrm{O}, 0 \cdot 02 ; \mathrm{MnSO}_{4} .4 \mathrm{H}_{2} \mathrm{O}, 0 \cdot 1 ; \mathrm{ZnSO}_{4} .7 \mathrm{H}_{2} \mathrm{O}, 0 \cdot 1$; $\mathrm{CaCO}_{3}, 1.8$ The carbon source for growth was either glucose or glycerol $\left(5\right.$ or $\left.10 \mathrm{~g} \mathrm{l}^{-1}\right)$.

Bacteria were grown under essentially anaerobic conditions in 1 litre screw-capped conical flasks containing $800 \mathrm{ml}$ medium and incubated at $30^{\circ} \mathrm{C}$ for $48 \mathrm{~h}$ with gentle mixing on a rotary shaker. For phototrophic growth of $R$. capsulatus, RCV medium (Weaver et al., 1975) supplemented with DL-malic acid $\left(4 \mathrm{~g}^{-1}\right)$ was used. For assessment of sulfoxides as respiratory electron acceptors under anaerobic conditions RCV medium without malate but supplemented with sodium propionate $(30 \mathrm{mM})(\mathrm{RCV} /$ propionate) and the appropriate sulfoxide $(10 \mathrm{mM})$ was used. Cultures were grown in glass bottles between two banks of tungsten lights. Bottles were completely filled to ensure that anaerobic conditions were obtained.

Purification of DMSO reductase from $R$. capsulatus. DMSO reductase was purified from $R$. capsulatus $\mathrm{H} 123$, a derivative strain of DSM 938 (Hudig et al., 1986), as described by McEwan et al. (1991) with the modifications of Bennett et al. (1994).

Enzyme assays. DMSO reductase activity was monitored spectrophotometrically using dithionite-reduced methyl viologen as electron donor as described by McEwan et al. (1985). Oxidation of reduced methyl viologen was monitored at $600 \mathrm{~nm}$ and an extinction coefficient of $13 \mathrm{mM}^{-1}$ (Jones \& Garland, 1976) used to calculate reaction rates. Kinetic constants for DMSO reductase were determined by the use of Lineweaver-Burk plots.

For experiments to determine the enantioselectivity of purified DMSO reductase a photocatalysed flavin-linked reaction system was devised. A gas-tight glass syringe $(5 \mathrm{ml})$ with a valve was filled with $3 \mathrm{ml}$ anaerobic Tris/ $\mathrm{HCl}(50 \mathrm{mM}$, $\mathrm{pH} 8.0)$ buffer containing EDTA $(10 \mathrm{mM})$. To this was added FMN $(250 \mu \mathrm{M}$ final concentration) and racemic sulfoxide (5-20 $\mathrm{mM}$ final concentration). The syringe was illuminated using tungsten light (three $100 \mathrm{~W}$ bulbs placed $20 \mathrm{~cm}$ from the syringe), resulting in the reduction of FMN (Penzer \& Radda, 1971). When FMN reduction was complete as judged by decolouration of the yellow solution the reaction was started by the introduction of a solution of DMSO reductase and the volume made up to $5 \mathrm{ml}$ with buffer. Samples were taken at intervals and analysed by HPLC.

Whole-cell reactions with sulfoxides. Following growth, bacteria were recovered by centrifugation and washed in potassium phosphate buffer $(100 \mathrm{mM}, \mathrm{pH} 7 \cdot 6)$. The recovered cell pellets were then resuspended in fresh buffer of the same composition to a concentration of $1-5 \mathrm{~g}$ dry cell weight $\mathrm{l}^{-1}$. In a typical reaction cell suspension $(20 \mathrm{ml})$ was transferred to a
$50 \mathrm{ml}$ serum bottle containing racemic sulfoxide $(40-60 \mathrm{mg})$; the bottle was sealed with a rubber stopper and the headspace flushed with nitrogen. Reaction mixtures were incubated at $35^{\circ} \mathrm{C}$ without agitation and samples taken at intervals for analysis by HPLC.

Analysis of reactants and products. The concentrations of sulfides and sulfoxides were determined by either HPLC or GC.

MMPSO, EPSO and their corresponding sulfides were analysed on a Spherisorb S5 ODS2 HPLC column $\left(250 \times 4.6 \mathrm{~mm}\right.$ ) eluted at a flow rate of $1 \mathrm{ml} \mathrm{min}^{-1}$ (eluant composition $50 \%$ acetonitrile, $50 \%$ sodium phosphate buffer, $25 \mathrm{mM}, \mathrm{pH} 7 \cdot 6$ ); detection was by UV absorption at $270 \mathrm{~nm}$. EPSO and the corresponding sulfide eluted at 2.4 and $6.5 \mathrm{~min}$ respectively. MMPSO and the corresponding sulfide eluted at 2.6 and $8.3 \mathrm{~min}$ respectively. MPTSO and the corresponding sulfide were analysed under the same conditions except that the eluant flow rate was decreased to $0.8 \mathrm{ml} \mathrm{min}^{-1}$ and the elution times were 5.0 and $18.0 \mathrm{~min}$ respectively. Samples were prepared for analysis by removal of cells by centrifugation followed by dilution of the supernatant in HPLC eluant.

MTMSO and the corresponding sulfide, bis(methylthio)methane, were analysed by GC on a J\&W Scientific DB5 column $(28 \mathrm{~m} \times 0.328 \mathrm{~mm}$, film thickness, $1.0 \mu \mathrm{m})$ using helium as carrier gas and flame ionization detection. The temperature programme consisted of an initial isothermal period, $150^{\circ} \mathrm{C}$ for $3 \mathrm{~min}$, followed by an increase to $200^{\circ} \mathrm{C}$ at a rate of $20^{\circ} \mathrm{C} \mathrm{min}{ }^{-1}$ and a final isothermal period of $2 \mathrm{~min}$. Samples were prepared for analysis by removal of cells by centrifugation, then the supernatant was diluted with an equal volume of aqueous 2,3-butanediol $\left(2 \mathrm{~g} \mathrm{l}^{-1}\right)$, which acted as internal standard. MTMSO eluted at $4.9 \mathrm{~min}$, the corresponding sulfide at $2.7 \mathrm{~min}$ and the internal standard at 2.2 min.

The optical purity of EPSO was determined using a Chiralcel OB HPLC column $(250 \times 4.6 \mathrm{~mm})$ eluted at a rate of $0.8 \mathrm{ml}$ $\min ^{-1}$ with hexane/2-propanol $(85: 15, \mathrm{v} / \mathrm{v})$. Detection was by UV absorption at $270 \mathrm{~nm}$. Ethyl 2-pyridyl sulfide eluted at 9.5 min whilst the enantiomers of EPSO eluted at 16.5 and $29.5 \mathrm{~min}$ (the absolute configuration of the two peaks was not assigned).

The optical purity of the other sulfoxides was determined using a Chiralcel OD HPLC column $(250 \times 4.6 \mathrm{~mm})$ eluted at a rate of $0.8 \mathrm{ml} \mathrm{min}^{-1}$ with hexane/ethanol $(95: 5, \mathrm{v} / \mathrm{v})$. Detection was by UV absorption at $270 \mathrm{~nm}$. Methoxymethyl phenyl sulfide eluted at $6.1 \mathrm{~min}$ whilst the enantiomers of MMPSO eluted at 24.3 and $28.7 \mathrm{~min}$. Methyl $p$-tolyl sulfide eluted at $5.9 \mathrm{~min} ;(R)$ - and $\langle(S\rangle$-MPTSO eluted at 15.5 and 17.1 min respectively. MTMSO enantiomers eluted at 31 and $32.5 \mathrm{~min}$ and were detected by UV absorption at $225 \mathrm{~nm}$; bis(methylthio)methane was not detectable by UV absorption.

\section{RESULTS AND DISCUSSION}

\section{Enantioselective reduction of racemic MPTSO by R. capsulatus DorA}

$R$. capsulatus DorA has a high sequence similarity to TMAO reductase (TorA) from $E$. coli $(45 \%$ sequence identity) (Shaw et al., 1996) but the enzymes differ in their substrate specificity. While the former is able to use both $S$-oxides and $N$-oxides (McEwan et al., 1985), the latter is highly specific for TMAO and does not use $S$ oxides at significant rates (Iobbi-Nivol et al., 1996). Although $R$. capsulatus DorA has only $29 \%$ sequence 


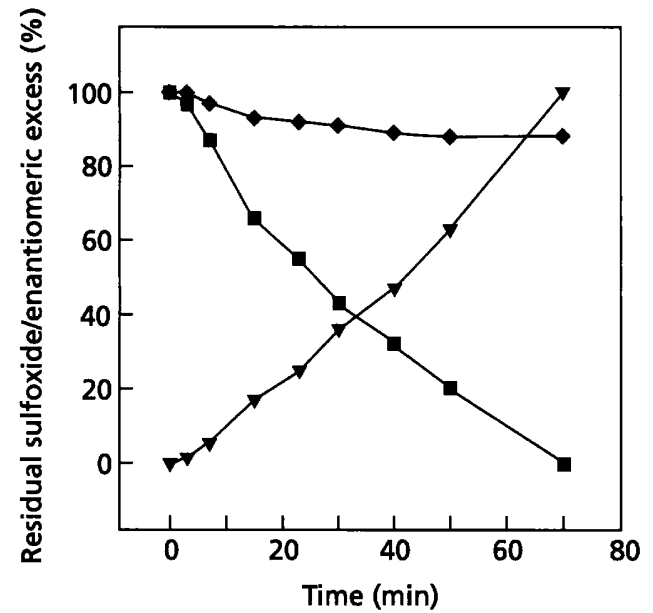

Fig. 2. Enantioselective reduction of racemic MPTSO by $R$. capsulatus DorA using photochemically reduced FMN as electron donor. $\bullet,(R)$-MPTSO; $\square,(S)$-MPTSO; $\nabla$, enatiomeric excess.

identity to E. coli DmsA (Shaw et al., 1996) the two enzymes exhibit a broad substrate specificity. The kinetic parameters of DorA from $R$. capsulatus and $R$. sphaeroides show that while the $k_{\text {cat }}$ values for the reduction of DMSO and TMAO are relatively close the $K_{\mathrm{m}}$ value for DMSO is in the micromolar range while the $K_{\mathrm{m}}$ for TMAO is in the millimolar range (Satoh \& Kurihara, 1987; Benson, 1993). In view of the broad substrate specificity of DMSO reductases, we were interested to determine whether the R. capsulatus DorA could catalyse the enantioselective reduction of racemic sulfoxides. An initial experiment was performed in which the kinetic parameters for the reduction of the enantiomers of MPTSO were determined. Although the $k_{\text {cat }}$ values for the enantiomers of MPTSO were similar the $K_{\mathrm{m}}$ value for (S)-MPTSO was about 100-fold lower than the $K_{\mathrm{m}}$ for $(R)$-MPTSO (data not shown). This observation was consistent with previous work by Abo et al. (1994), who showed that $R$. sphaeroides DorA catalysed the stereoselective removal of $(S)$-methyl phenyl sulfoxide from a racemic mixture.

The observation that DorA had different kinetic parameters with the two enantiomers of MPTSO suggested that treatment of racemic MPTSO with $R$. capsulatus DorA would result in the relative enrichment of the $(R)$ enantiomer due to the more rapid reduction of the $(S)$ enantiomer. This was tested using purified DorA in a photochemically driven reaction system with $\mathrm{FMNH}_{2}$ as electron donor. Samples were removed from the reaction at intervals and analysed by HPLC to determine the extent of reduction and the ratio of enantiomers. Fig. 2 shows that $(S)$-MPTSO decreased far more rapidly with time than the $(R)$-MPTSO; this is consistent with the kinetic results using pure enantiomers. The $(R)$-MPTSO was produced with an enantiomeric excess of $100 \%$, with an $88 \%$ recovery of this enantiomer.

\section{Anaerobic phototrophic growth of $R$. capsulatus using various sulfoxides as auxiliary oxidants}

DMSO respiration is one of several anaerobic respiratory pathways which have been identified in Rhodobacter (reviewed by McEwan, 1994). The use of electron acceptors such as DMSO is not essential for anaerobic phototrophic growth but their reduction can facilitate anaerobic growth on reduced carbon sources such as propionate or butyrate (Richardson et al., 1988). As a consequence, these electron acceptors have been described as auxiliary oxidants (McEwan et al., 1985). The requirement of an auxiliary oxidant for growth on propionate opened the way for screening a range of sulfoxides as potential substrates for DorA. A series of growth curves was obtained for the phototrophic growth of $R$. capsulatus DSM 938 on RCV/propionate medium. In the absence of auxiliary oxidants no growth was observed whilst in the presence of DMSO the doubling time was $4 \mathrm{~h}$. Four sulfoxides tested supported anaerobic growth, albeit with longer doubling times than observed with DMSO. These were MPTSO $\left(t_{\mathrm{d}}\right.$ $12 \mathrm{~h}), \operatorname{MPTSO}\left(t_{\mathrm{d}} 12 \mathrm{~h}\right)$, methionine sulfoxide $\left(t_{\mathrm{d}} 7.5 \mathrm{~h}\right)$

Table 1. Enantioselective reduction of MPTSO by whole cells of $R$. capsulatus, E. coli and P. mirabilis

$R$. capsulatus was grown phototrophically on RCV medium supplemented with yeast extract $(2 \mathrm{~g}$ $\left.\mathrm{I}^{-1}\right)$ and glucose $\left(10 \mathrm{~g}^{-1}\right)$. Enteric bacteria were grown on a basal medium supplemented with Casamino acids $\left(1.5 \mathrm{~g} \mathrm{l}^{-1}\right)$, plus glucose $\left(5 \mathrm{~g} \mathrm{l}^{-1}\right)$ for $P$. mirabilis and glycerol $\left(5 \mathrm{~g} \mathrm{l}^{-1}\right)$ for E. coli. Concentrations of MPTSO enantiomers are given in $\mathrm{mg} \mathrm{ml}^{-1}$. -, No measurement made.

\begin{tabular}{|c|c|c|c|c|c|c|}
\hline \multirow[t]{2}{*}{ Time (h) } & \multicolumn{2}{|c|}{ E. coli } & \multicolumn{2}{|c|}{ P. mirabilis } & \multicolumn{2}{|c|}{ R. capsulatus } \\
\hline & $\begin{array}{c}(\boldsymbol{R})- \\
\text { MPTSO }\end{array}$ & $\begin{array}{c}(S)- \\
\text { MPTSO }\end{array}$ & $\begin{array}{c}(\boldsymbol{R})- \\
\text { MPTSO }\end{array}$ & $\begin{array}{c}(\boldsymbol{S})- \\
\text { MPTSO }\end{array}$ & $\begin{array}{c}(\boldsymbol{R})- \\
\text { MPTSO }\end{array}$ & $\begin{array}{c}(S)- \\
\text { MPTSO }\end{array}$ \\
\hline 0 & 0.74 & 0.74 & 0.74 & 0.74 & $0 \cdot 25$ & 0.25 \\
\hline 0.25 & - & - & - & - & 0.20 & 0 \\
\hline 4 & 0.27 & 0.63 & 0.08 & 0.72 & - & - \\
\hline 20 & 0 & 0.45 & 0 & 0.58 & - & - \\
\hline
\end{tabular}



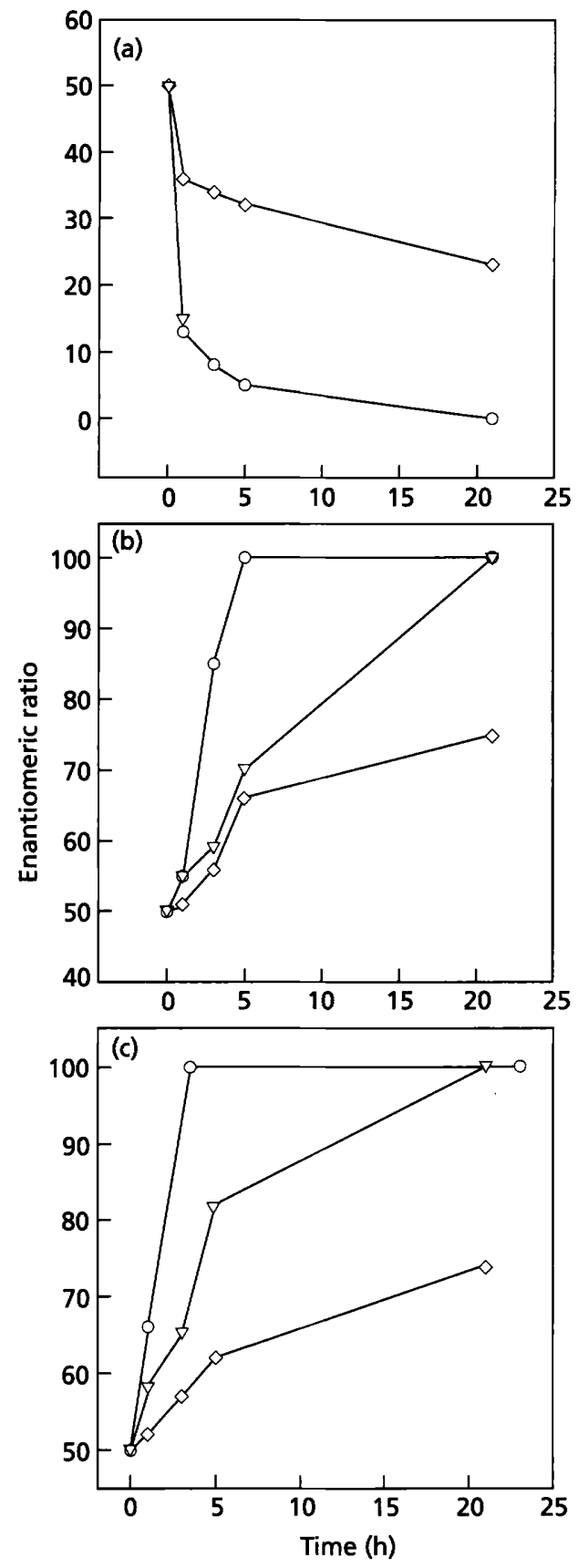

Fig. 3. Enantioselective reduction of sulfoxides by whole cells of $R$. capsulatus (a), $E$. coli (b) and $P$. vulgaris (c). The enantiomeric ratio refers to proportion of one enantiomer as a percentage of the total racemic mixture as determined by chiral HPLC, under starting conditions where each enantiomer represented $50 \%$ of the mixture. The figure shows the decrease in the $28.7 \mathrm{~min}, 32.5 \mathrm{~min}$ and $16.5 \mathrm{~min}$ elution peaks of one enantiomer of MMPSO $(\diamond)$, MTMSO $(\nabla)$ and EPSO $(0)$ respectively. (a) $R$. capsulatus was grown phototrophically in RCV medium supplemented with yeast extract $\left(2 \mathrm{~g}^{-1}\right)$ and glucose $\left(10 \mathrm{~g} \mathrm{I}^{-1}\right)$. Concentrations of sulfoxides at the beginning of the experiment were: EPSO, $3.2 \mathrm{mg} \mathrm{ml}^{-1}$; MMPSO, $2.3 \mathrm{mg}$ $\mathrm{ml}^{-1}$; and MTMSO, $2.4 \mathrm{mg} \mathrm{ml}^{-1}$. (b, c) $E$. coli and $P$. vulgaris were grown on a basal medium supplemented with glucose $\left(10 \mathrm{~g} \mathrm{I}^{-1}\right)$ and yeast extract $\left(2 \mathrm{~g} \mathrm{l}^{-1}\right)$. Concentrations of sulfoxides at the beginning of the experiment were: EPSO, $2.6 \mathrm{mg} \mathrm{ml}^{-1}$; MMPSO, $2.5 \mathrm{mg} \mathrm{ml}^{-1}$; and MTMSO, $2.4 \mathrm{mg} \mathrm{ml}^{-1}$. and tert-butyl methyl sulfoxide (doubling time not determined).

Although racemic MPTSO supported growth with a doubling time of $12 \mathrm{~h}$ no growth was observed over a period of $45 \mathrm{~h}$ when $(R)$-MPTSO was supplied as auxiliary oxidant. This is consistent with the demonstrated enantioselectivity of DorA from $R$. capsulatus. Similarly, Simala-Grant \& Weiner (1996) have shown that a variety of $\mathrm{N}$-oxides and $S$-oxides can support anaerobic growth of $E$. coli and this must involve the use of DmsABC in respiration.

\section{Resolution of racemic sulfoxides by whole cells of $R$. capsulatus, E. coli and Proteus sp.}

The enantioselective reduction of MPTSO by DorA from $R$. capsulatus prompted us to investigate the enantioselectivity of other bacterial $S$-oxide reductases. E. coli, P. mirabilis and P. vulgaris were selected for investigation and compared with $R$. capsulatus DSM 938 using a range of sulfoxide substrates. It was already known that $E$. coli DmsABC could reduce a number of racemic sulfoxides and $\mathrm{N}$-oxides (Simala-Grant \& Weiner, 1996) but nothing was known about its enantioselectivity. In order to avoid the need to purify the enzymes these reactions were carried out using whole cells. All of the bacteria were able to reduce the four racemic sulfoxides (MPTSO, MTMSO, MMPSO and EPSO) in an enantioselective way. As expected, $R$. capsulatus used the (S)-MPTSO enantiomer in preference to the $(R)$-enantiomer (Table 1 ) but surprisingly it was observed that $E$. coli carried out a reaction which was enantiocomplementary and resulted in the preferential removal of the $(R)$-MPTSO (Table 1 ). In view of the latter result a second enteric bacterium, P. mirabilis, was investigated to determine whether its enantioselectivity was similar to that of $R$. capsulatus or E. coli (Table 1). It was found that, like E. coli, P. mirabilis preferentially removed $(R)$-MPTSO (Table 1 ).

Further experiments to investigate the resolution of the three other racemic sulfoxides showed that the enantioselectivity of R. capsulatus was opposite to that of E. coli and $P$. vulgaris. Although the absolute configuration of the enantiomers was not determined they were characterized by their distinct elution times during resolution by chiral HPLC. Fig. 3(a) shows that with $R$. capsulatus for EPSO, MMPSO and MTMSO there was a decrease in the percentage of one enantiomer in each racemic mixture. Thus, in the case of EPSO, one enantiomer (16.5 min elution peak) within the mixture began as $50 \%$ of the total but decreased until it formed almost a zero proportion of the mixture. A similar result was obtained for MTMSO (decrease in the 32.5 min elution peak) while in the case of MMPSO (decrease in the 28.7 min elution peak) the percentage of this racemate within the mixture was $30 \%$ at the end of the experiment. Although the configuration of the enantiomers which were removed was not established it seems likely, in view of the results with MPTSO, that it was the $(S)$ racemate which was removed. In contrast, Fig. 3(b) 
shows that for E. coli the same enantiomers within each racemic mixture which decreased most rapidly in racemic mixtures treated with $R$. capsulatus were observed to increase as a percentage of the total. This indicates that the E. coli cells were removing the opposite enantiomer of each sulfoxide compared to $R$. capsulatus. The results for the $P$. vulgaris cells (Fig. $3 \mathrm{c}$ ) were similar to those with $E$. coli. Taken together, these data show that the enantioselectivity of $R$. capsulatus chiral sulfoxides is opposite to that of E. coli and P. vulgaris. Since it is established that $E$. coli TMAO reductase is unable to reduce $S$-oxides while DmsABC has broad specificity towards these substrates, including MPTSO (Simala-Grant \& Weiner, 1996), it seems highly likely that this enzyme was responsible for the enantioselective reduction of these racemic sulfoxides. However, we cannot rule out the possibility that other cytoplasmic $S$ oxide reductases, such as biotin sulfoxide reductase, which have been identified in the $E$. coli genome (Blattner et al., 1997) made a minor contribution to the reduction of the racemic sulfoxides. Results using $P$. vulgaris and $P$. mirabilis were broadly similar to those for $E$. coli (Table 1, Fig. 3), suggesting that the properties of the Proteus $S$-oxide/ $N$-oxide reductase was closely related to that of the E. coli DmsABC. This is consistent with previous studies of DMSO reductase in $P$. vulgaris which characterized a membrane-bound enzyme which was able to reduce both DMSO and TMAO (Styrvold \& Strom, 1984). It is notable that in all three systems both alkylaryl and dialkyl sulfoxides were resolved. Although we did not investigate diaryl sulfoxide reduction, Simala-Grant \& Weiner (1996) have shown that diphenyl sulfoxide is reduced at an extemely low rate by DmsABC of E. coli.

\section{Concluding remarks}

In this paper we have shown that DMSO reductases from purple phototrophic bacteria and enteric bacteria catalyse the enantioselective reduction of racemic sulfoxides with opposite stereospecificity. The determination of the structure of DorA with DMSO bound (McAlpine et al., 1998) opens the way for molecular modelling of the binding of chiral sulfoxides to this enzyme; this work should provide a deeper insight into the molecular basis of enantioselectivity in $R$. capsulatus DorA. Further comparisons with DmsA will also be informative in gaining an understanding of the molecular basis for the difference in enantioselectivity between DorA and DmsABC. It will also be interesting to investigate the enantioselectivity of DMSO reductases towards chiral $\mathrm{N}$-oxides.

\section{ACKNOWLEDGEMENTS}

S.P.H. was supported by a CASE studentship from SERC (UK) and Zeneca BioProducts. A.L.S. thanks the Australian Research Council for a postgraduate award.

\section{REFERENCES}

Abo, M., Tachibana, M., Okubo, A. \& Yamazaki, S. (1994). Enantioselective reduction of the sulfoxide to sulfide in methyl phenyl sulfoxide by dimethylsulfoxide reductase from $R$ hodobacter sphaeroides f.s. denitrificans. Biosci Biotechnol Biochem 58, 596-597.

Abo, M., Tachibana, M., Okubo, A. \& Yamazaki, S. (1995). Enantioselective deoxygenation of alkyl aryl sulfoxides by DMSO reductase from $R$ hodobacter sphaeroides f.s. denitrificans. Bioorg Med Chem 3, 109-112.

Bennett, B., Benson, N., McEwan, A. G. \& Bray, R. C. (1994). Multiple states of the molybdenum centre of dimethylsulfoxide reductase from Rhodobacter capsulatus revealed by EPR spectroscopy. Eur J Biochem 225, 321-331.

Benson, N. (1993). Biochemical and spectroscopic studies of dimethylsulphoxide reductase from Rhodobacter capsulatus. $\mathrm{PhD}$ thesis, University of East Anglia.

Bevinakatti, H. S. \& Banerji, A. A. (1991). Practical chemoenzymatic synthesis of both enantiomers of propanolol. $J$ Org Chem 56, 5372-5375.

Blattner, F. R., Plunkett, G., 3rd, Bloch C. A. \& 14 other authors (1997). The complete genome sequence of Escherichia coli K-12. Science 277, 1453-1474.

Burgess, K., Henderson, I. \& Ho, K.-K. (1992). Biocatalytic resolutions of sulfinylalkonoates: a facile route to optically active sulfoxides. J Org Chem 57, 1290-1295.

Butlin, R. J., Linney, I. D., Mahon, M. F., Tye, H. \& Wills, M. (1996). Recoverable chiral sulfoxides for asymmetric synthesis: application to stereoselective carbonyl reduction and the asymmetric synthesis of allylic alcohols. J Chem Soc Perkins Trans 1, 95-105.

Carreno, M. C. (1995). Applications of sulfoxides to asymmetric synthesis of biologically active compounds. Chem Rev 95, $1717-1760$

Colonna, S., Gaggero, N., Manfredi, A., Casella, L., Gullotti, M., Carrea, G. \& Pasta, P. (1990). Enantioselective oxidations of sulfides catalysed by chlorperoxidase. Biochemistry 29, 10465-10468.

Crosby, J (1992). Chirality in industry - an overview. In Chirality in Industry, vol. 1, pp. 1-66. Edited by A. N. Collins, G. N. Sheldrake \& J. Crosby. Chichester: Wiley.

Hanlon, S. P. (1993). Physiology and biochemistry of dimethylsulfide oxidation and dimethylsulfoxide reduction by Rhodobacter species. PhD thesis, University of East Anglia.

Holland, H. L. (1988). Chiral sulfoxidation by biotransformation of organic sulfides. Chem Rev 88, 473-485.

Holland, H. L., Brown, F. M. \& Larsen, B. G. (1995). Biotransformation of organic sulfides. 6. Formation of chiral para substituted benzyl methyl sulfoxides by Helminthosporium species NRRL 4671. Tetrabedron Asymmetry 6, 1561-1567.

Hudig, H., Kaufmann, N. \& Drews, G. (1986). Respiratory deficient mutants of Rhodopseudomonas capsulata. Arch Microbiol 145, $378-385$.

lobbi-Nivol, C., Pommier, J., Simala-Grant, J., Mejean, V. \& Giordano, G. (1996). High substrate specificity and induction characteristics of trimethylamine- $N$-oxide reductase of Escherichia coli. Biochim Biophys Acta 1294, 77-82.

Jones, R. W. \& Garland, P. B. (1976). Sites and specificity of the reaction of bipyridylium compounds with anaerobic respiratory enzymes of Escherichia coli. Effects of permeability barriers imposed by the cytoplasmic membrane. Biochem J 164, 199-211. 
McAlpine, A. S., McEwan, A. G., Shaw, A. L. \& Bailey, S. (1997). Molybdenum active centre of DMSO reductase from $R$ hodobacter capsulatus: crystal structure of the oxidised enzyme at $1.82 \AA$ resolution and the dithionite-reduced enzyme at $2.8 \AA$ resolution. J Biol Inorg Chem 2, 690-701.

McAlpine, A. S., McEwan, A. G. \& Bailey, S. (1998). The high resolution crystal structure of DMSO reductase in complex with DMSO. J Mol Biol 275, 613-623.

McEwan, A. G. (1994). Photosynthetic electron transport and anaerobic metabolism in purple non-sulfur phototrophic bacteria. Antonie Leeuwenhoek 66, 151-164.

McEwan, A. G., Wetzstein, H.-G., Jackson, J. B. \& Ferguson, S. J. (1985). Periplasmic location of the terminal reductase in trimethylamine- $N$-oxide and dimethylsulfoxide respiration in the photosynthetic bacterium Rhodopseudomonas capsulata. Biochim Biophys Acta 806, 410-417.

McEwan, A. G., Ferguson, S. J. \& Jackson, J. B. (1991). Purification and properties of dimethylsulphoxide reductase from $R$ hodobacter capsulatus. Biochem J 207, 305-307.

Penzer, G. R. \& Radda, G. K. (1971). Photochemistry of flavins. Methods Enzymol 18B, 479-495.

Pitchen, P., France, C. J., McFarlane, I. M., Newton, C. G. \& Thompson, D. M. (1994). Large scale synthesis of a biologically active sulfoxide. Tetrabedron Lett 35, 485-488.

Richardson, D. J., King, G. F., Kelly, D. J., McEwan, A. G., Jackson, J. B. \& Ferguson, S. J. (1988). The role of auxiliary oxidants in maintaining redox balance during phototrophic growth of Rhodobacter capsulatus on propionate and butyrate. Arch Microbiol 150, 130-137.

Roberts, S. M., Turner, N. J., Willets, A. J. \& Turner, M. K. (1995). Introduction to Biocatalysis Using Enzymes and Microorganisms. Cambridge: Cambridge University Press.

Rossi, C., Fauve, A., Madesclaire, M., Roche, D., Davis, F. A. \& Reddy, R. T. (1992). Microbiological and chemical methods in the asymmetric oxidation of sulfides: a comparative study for the preparation of (S)-vinyl sulfoxides. Tetrabedron Asymmetry 3, $629-636$.
Satoh, T. \& Kurihara, F. N. (1987). Purification and properties of dimethylsulfoxide reductase containing a molybdenum cofactor from a photodenitrifier, Rhodobacter sphaeroides f.s. denitrificans. J Biochem 102, 191-197.

Schindelin, H., Kisker, C., Hilton, J. C., Rajagopalan, K. V. \& Rees, D. C. (1996). Crystal structure of DMSO reductase: redox-linked changes in molybdopterin coordination. Science 272, 1615-1621.

Schneider, F., Lowe, J., Huber, J., Schindelin, H., Kisker, C. \& Knaeblein, J. (1996). Crystal structure of dimethylsulfoxide reductase from Rbodobacter capsulatus at $1.88 \AA$ resolution. J Mol Biol 263, 53-69.

Shaw, A. L., Hanson, G. R. \& McEwan, A. G. (1996). Cloning and sequence analysis of the dimethylsulfoxide reductase structural gene from Rhodobacter capsulatus. Biochim Biophys Acta 1276, 176-180.

Simala-Grant, J. L. \& Weiner, J. H. (1996). Kinetic analysis and substrate specificity of Escherichia coli dimethylsulfoxide reductase. Microbiology 142, 3231-3239.

Solladie, G. (1981). Asymmetric synthesis using nucleophilic reagents containing a chiral sulfoxide group. Synthesis 3, 185-196.

Styrvold, O. B. \& Strom, A. R. (1984). Dimethylsulphoxide and trimethylamine-N-oxide respiration of Proteus vulgaris. Arch Microbiol 140, 74-78.

Weaver, P. F., Wall, J. D. \& Gest, H. (1975). Characterisation of Rhodopseudomonas capsulata. Arch Microbiol 105, 207-216.

Weiner, J., Maclsaac, D. P., Bishop, R. E. \& Bilous, P. T. (1988). Purification and properties of dimethylsulfoxide reductase, an iron-sulfur molybdoenzyme of Escherichia coli. J Bacteriol 170, 1505-1510.

Weiner, J., Rothery, R. A., Sambasivarao, D. \& Trieber, C. A. (1992). Molecular analysis of dimethylsulfoxide reductase: a complex iron-sulfur molybdoenzyme of Escherichia coli. Biochim Biophys Acta 1102, 1-18.

Received 1 December 1997; revised 23 March 1998; accepted 14 April 1998. 